Georgia State University

ScholarWorks @ Georgia State University

\title{
Associations between Multiple Dimensions of Schizotypy and Sociodemographic Variables in a Non-Psychiatric Sample of Young Adults
}

Sandra M. Goulding

Emory University, sandra.m.goulding@emory.edu

Erin Tone

Georgia State University, etone@gsu.edu

Michael T. Compton

Emory University

Follow this and additional works at: https://scholarworks.gsu.edu/psych_facpub

Part of the Psychology Commons

\section{Recommended Citation}

Goulding, Sandra M.; Tone, Erin; and Compton, Michael T., "Associations between Multiple Dimensions of Schizotypy and Sociodemographic Variables in a Non-Psychiatric Sample of Young Adults" (2009).

Psychology Faculty Publications. 132.

https://scholarworks.gsu.edu/psych_facpub/132

This Article is brought to you for free and open access by the Department of Psychology at ScholarWorks @ Georgia State University. It has been accepted for inclusion in Psychology Faculty Publications by an authorized administrator of ScholarWorks @ Georgia State University. For more information, please contact scholarworks@gsu.edu. 
RUNNING TITLE: Schizotypy and Sociodemographic Variables

Associations between Multiple Dimensions of Schizotypy and Sociodemographic Variables in a Non-Psychiatric Sample of Young Adults

Sandra M. Goulding, M.P.H. ${ }^{a}$

Erin McClure-Tone, Ph.D. ${ }^{\mathrm{b}}$

Michael T. Compton, M.D., M.P.H. ${ }^{\mathrm{a}}$

${ }^{\text {a }}$ Emory University School of Medicine, Department of Psychiatry and Behavioral Sciences, Atlanta, Georgia, United States of America

${ }^{\mathrm{b}}$ Georgia State University, Department of Psychology, Atlanta, Georgia, United States of America

Corresponding Author

Michael T. Compton, M.D., M.P.H.

Emory University School of Medicine

Department of Psychiatry and Behavioral Sciences

49 Jesse Hill Jr. Drive, S.E., Room \#333

Atlanta, GA 30303

TEL: 404-778-1486 / FAX: 404-616-3241

E-MAIL: Michael.Compton@emory.edu 


\section{Abstract}

Title: Associations between Multiple Dimensions of Schizotypy and Sociodemographic Variables in a Non-Psychiatric Sample of Young Adults

Sandy and Michael to write Abstract prior to submission.

Key Words: Perceptual Aberration Scale; Schizotypal Personality Questionnaire; Schizotypy; Social Anhedonia Scale 


\section{Introduction}

Schizotypy is a multidimensional personality construct with a continuous distribution in non-clinical and clinical samples (Gooding and Iacono, 1995; Sanchez-Bernardos and Avia, 2006). Biological relatives of individuals with schizophrenia exhibit more schizotypal traits than those without a family history of the disorder, suggestive of a genetic relationship between schizotypy and schizophrenia (Clementz et al., 1991; Kendler et al., 1995; Silverman et al., 1993). Furthermore, subclinical attenuated psychotic experiences of individuals with schizotypy resemble the symptomatology of schizophrenia (Claridge et al., 1996; Kendler et al., 1995; Raine et al., 1994; Vollema and Van den Bosch, 1995).

Gender differences in self-reported schizotypal dimension scores have been reported in several prior studies (Claridge and Hewitt, 1987; Maric et al., 2003; Mason and Claridge, 2006; Muntaner et al., 1988; Raine, 1992; Young et al., 1986), with females tending to score higher on measures of positive schizotypy and males scoring higher on negative schizotypy scales. Associations between age and schizotypy have been mixed (Mason and Claridge, 2006; Mata et al., 2005), though studies across multiple age groups generally suggest that younger individuals tend to score higher in schizotypy, especially positive schizotypy. Schizotypal domains appear to manifest consistently across racial/ethnic groups (Chmielewski et al., 1995). Associations between higher levels of schizotypy and fewer social supports, poorer overall social adjustment, lower rates of dating or marriage, and lower quality of intimate relationships have been reported (Horan et al., 2007; Kwapil et al., 2008; Mishlove and Chapman, 1985).

The present study examined the ways in which multiple dimensions of schizotypy are associated with basic sociodemographic characteristics in a culturally diverse, non-psychiatric sample of young adults. Based on prior research, it was expected that: (1) females would score 
higher on perceptual aberration than males, whereas males would score higher on social anhedonia, and (2) age would have a negative association with positive schizotypy scores. Potential associations between race/ethnicity and scores on various schizotypal domains were examined. In addition, it was anticipated that individuals who were single would score higher in schizotypy than those in a relationship, and that those with a past history of mental health treatment would score higher in schizotypy than those without. Information on basic correlates of schizotypy such as these may benefit future research, and some have suggested that more research is needed on the relations between schizotypal traits and demographic characteristics such as gender and age (Fonseca-Pedrero et al., 2008).

\section{Methods}

Participants included 950 undergraduate students enrolled in introductory psychology classes at an urban university in the southeastern United States between January and December 2007. Students were invited to participate via a recruitment statement on an online program used to manage the undergraduate research pool at the university. Participants read an online consent form approved by the university's Institutional Review Board before proceeding to the survey. The order of measures was randomized across participants and automated data entry produced computerized files for data cleaning and analysis. To enhance comparison with previous research on schizotypal dimensions in undergraduate populations, only those respondents aged 18-26 years were included in the analyses. Additionally, participants taking $<20$ minutes to complete the full assessment battery (which typically took at least 30 minutes) were excluded. These restrictions resulted in a final sample of 825 students.

Basic demographic data were obtained (age, gender, race/ethnicity, and relationships status), and students were asked, "Have you ever seen a counselor, psychotherapist, 
psychologist, or psychiatrist for emotional problems, nervous problems, anxiety, depression, or other mental health problems?” Three reliable and valid self-report scales, utilized in prior nonclinical and clinical samples, provided data on schizotypal dimensions: the Schizotypal Personality Questionnaire (SPQ; Raine, 1991), the Perceptual Aberration Scale (PAS; Chapman et al., 1978), and the Revised Social Anhedonia Scale (RSAS; Eckblad et al., 1982). A recent confirmatory factor analysis of the SPQ in this sample (Compton et al., 2008) revealed that a four-factor model—including paranoid, cognitive-perceptual, interpersonal, and disorganized domains_-best fits the data.

Associations among the six schizotypy measures (the four SPQ domains, the PAS, and the RSAS) and sociodemographic variables were analyzed using six separate stepwise multiple linear regression models, with sociodemographic variables and past treatment history as predictors of schizotypy domains. Due to difficulties in interpretation, the heterogeneous "biracial/multiracial" and "other" categories of the race/ethnicity variable were excluded and the four remaining categories were recoded using dummy variables. Further, the relationship status variable was collapsed and participants were categorized as either in a relationship or single and not dating anyone regularly. All analyses were conducted using SPSS 15.0.

\section{Results}

Basic demographic characteristics of the sample and descriptive statistics for the schizotypy scale scores are shown in Table 1. The mean age of participants was $20.1 \pm 1.7$ years, and $77.2 \%$ of the sample was female. Self-reported race/ethnicity and relationship status also are shown. Just over one-quarter (28.4\%) of participants reported a history of mental health treatment. Mean total SPQ, PAS, and SAS total scores were 23.0 $\pm 13.6,4.5 \pm 4.7$, and 8.7 \pm 6.0 , respectively. 
For each regression model, age, gender, race/ethnicity, relationship status, and history of mental health treatment were entered in a stepwise fashion. Findings are shown in Table 2. History of mental health treatment was the only independently significant predictor of the SPQ paranoid, cognitive-perceptual, and interpersonal domains. SPQ disorganized schizotypy was predicted by history of treatment, in addition to race/ethnicity (Black/African American participants had lower scores) and relationship status (those in a relationship had lower scores). Of note, relationship status and history of mental health treatment were associated $\left(\chi^{2}=9.28\right.$, $d f=1, p=.002$ ), with those in a relationship being less likely to have been in treatment (32.7\%) than those who were single (23.1\%). Regarding PAS scores, race/ethnicity was the only significant predictor, with Black/African American participants having lower scores. For the RSAS, race/ethnicity and gender were significant predictors—White/Caucasian participants and female participants had lower social anhedonia scores.

\section{Discussion}

Several key findings emerged from this study: (1) history of mental health treatment was the only significant independent predictor of paranoid, cognitive perceptual, and interpersonal schizotypy, indicating little influence of gender, age, race/ethnicity, and relationship status in this sample; (2) race, relationship status and history of mental health treatment were significant independent predictors of disorganized schizotypy, with Black/African Americans scoring lower than all other racial/ethnic groups and those who were single scoring higher than those in a relationship; (3) race was the only independently significant predictor for perceptual aberrations, with Black/African Americans scoring lower than all other racial/ethnic groups; and (4) race and gender were significant independent predictors of social anhedonia, with White/Caucasian 
Americans scoring lower than all other racial/ethnic groups and males scoring higher than females.

Although an age effect on schizotypy dimensions was not observed, this may have resulted from the limited age range of this sample. While gender differences in multiple schizotypy domains were expected, the isolated finding pertaining to social anhedonia was consistent with previous research demonstrating that males score higher on scales reflecting social anhedonia (Chapman et al., 1976; Chmielewski et al., 1995; Claridge et al., 1996; Kwapil et al., 2008; Muntaner et al., 1988). The relationship between race/ethnicity and PAS scores was consistent with some prior research, while the association between race/ethnicity and RSAS scores was contradictory (Chmielewski et al., 1995). However, a recent study by Kwapil and colleagues (2008), involving 6,137 undergraduate students at the University of North Carolina at Greensboro, documented that African American race/ethnicity predicted higher scores on both the PAS and the RSAS. Thus, although the literature appears to report fairly consistently that African Americans in this age range have higher SAS scores, findings pertaining to race/ethnicity and PAS scores are discrepant, for reasons that remain unclear.

Fonseca-Pedrero and colleagues (2008) examined the role of gender and age across multiple dimensions of schizotypy in adolescents. Studying 321 Spanish students in public secondary schools, aged 12-17 years (mean, 13.8 \pm 1.3 ), they found that boys scored higher than girls on scales measuring impulsive nonconformity, aberrant beliefs, and physical and social anhedonia, whereas girls scored higher on positive schizotypy, social paranoia, and negative evaluation. Though the present study, examining fewer dimensions of schizotypy, found only one association with gender (higher social anhedonia in males), it concurred with the finding of Fonseca-Pedrero and colleagues. Together, these studies indicate that males have higher levels of 
social anhedonia in both adolescence and in the college years. Whereas Fonseca-Pedrero and colleagues (2008) found multiple associations with age, generally indicating that as participants' ages increased so did their schizotypy scores, the present study found no age associations. This could indicate that although adolescence is a period when schizotypal traits evolve, such traits are relatively stable by the time of young adulthood.

Several methodological limitations, inherent to the study design, should be noted: (1) self-report measures of schizotypy were use rather than a clinical assessment, and some aspects of schizotypy may not be fully acknowledged or endorsed by those who have such traits; (2) the restrictive age criteria (18-26 years) may have obfuscated associations between age and schizotypal dimensions that would be apparent in the general population; and (3) relationship status and history of mental health treatment were dichotomized to facilitate analysis. Despite these limitations, findings from the current investigation suggest a need for further study of individual differences in the expression of schizotypal dimensions within culturally diverse, nonclinical samples. Future research should consider the potential influence of gender and race/ethnicity as predictors of schizotypy, and the ways in which such demographic correlates may shape the field's articulation of a comprehensive schizotypy construct. 


\section{References}

Chapman LJ, Chapman JP, Raulin, ML (1976) Scales for physical and social anhedonia. $J$ Abnorm Psychol. 85:374-382.

Chapman LJ, Chapman JP, Raulin ML (1978) Body-image aberration in schizophrenia. $J$ Abnorm Psychol. 87:399-407.

Chmielewski PM, Fernandes LO, Yee CM, Miller GA (1995) Ethnicity and gender in scales of psychosis proneness and mood disorders. J Abnorm Psychol. 104: 464-470.

Claridge GS, Hewitt JK (1987) A biometrical study of schizotypy in a normal population. Person Individ Dif. 8:303-312.

Claridge G, McCreery C, Mason O, Bentall R, Boyle G, Slade P, Popplewell D (1996) The factor structure of 'schizotypal' traits: A large replication study. Br J Clin Psychol. 35:103-115.

Clementz BA, Grove WM, Katsanis J, Iacono WG (1991) Psychometric detection of schizotypy: Perceptual aberration and physical anhedonia in relatives of schizophrenics. J Abnorm Psychol. 100:607-612.

Compton MT, Goulding SM, McClure-Tone E, Bakeman R (2008) Measuring schizotypy: Psychometric properties and factorial structure of three self-report rating scales in nonpsychiatric young adults (submitted for publication).

Eckblad ML, Chapman LJ, Chapman JP, Mishlove M (1982) The revised social anhedonia scales. (Available from LJ Chapman, Department of Psychology, 1202 West Johnson Street, University of Wisconsin, Madison, WI 53706).

Fonseca-Pedrero E, Lemos-Giráldez S, Muñiz J, García-Cueto E, Campillo-Álvarez A (2008) Schizotypy in adolescence: The role of gender and age. J Nerv Ment Dis. 196:161-165. 
Gooding DC, Iacono WG (1995) Schizophrenia through the lens of a developmental psychopathology perspective. In DJ Cohen, D Cicchetti (Eds) Developmental Psychopathology (pp 535-580). New York: John Wiley \& Sons.

Horan WP, Brown SA, Blanchard JJ (2007) Social anhedonia and schizotypy: The contribution of individual differences in affective traits, stress, and coping. Psychiatry Res. 149:147156.

Kendler KS, McGuire M, Gruenberg AM, Walsh D (1995) Schizotypal symptoms and signs in the Roscommon Family Study: Their factor structure and familial relationship with psychotic and affective disorders. Arch Gen Psychiatry. 52:296-303.

Kwapil TR, Barrantes-Vidal N, Silvia PJ (2008) The dimensional structure of the Wisconsin Schizotypy Scales: Factor identification and construct validity. Schizophr Bull. 34:444457.

Maric N, Krabbendam L, Vollebergh W, De Graff R, va Os J (2003) Sex differences in symptoms of psychosis in non-selected, general population sample. Schizophr Res. 63:89-95.

Mason O, Claridge G (2006) The Oxford-Liverpool Inventory of Feelings and Experiences (OLIFE): Further description and extended norms. Schizophr Res. 82:203-211.

Mata I, Mataix-Cols D, Peralta V (2005) Schizotypal Personality Questionnaire-Brief: Factor structure and influence of sex and age in a nonclinical population. Pers Individ Dif. 38:1183-1192.

Mishlove M, Chapman LJ (1985) Social anhedonia in the prediction of psychosis proneness. $J$ Abnorm Psychol. 107:305-311. 
Muntaner C, Garcia-Sevilla L, Fernandez A, Torrubia R (1988) Personality dimensions, schizotypal and borderline personality traits and psychosis proneness. Pers Indiv Dif. 9:257-268.

Raine A (1991) The SPQ: A scale for the assessment of schizotypal personality based on DSMIII-R criteria. Schizophr Bull. 17:555-564.

Raine A (1992) Sex differences in schizotypal personality in a nonclinical population. J Abnorm Psychol. 101:361-364.

Raine A, Reynolds C, Lencz T, Scerbo A, Triphon N, Kim D (1994) Cognitive-perceptual, interpersonal, and disorganized features of schizotypal personality. Schizophr Bull. 20:191-201.

Sanchez-Bernardos ML, Avia MD (2006) The relationship between fantasy proneness and schizotypy in adolescents. J Nerv Ment Dis. 194:411-414.

Silverman JM, Siever LJ, Horvath TB, Coccaro EF, Klar HM, Davidson M, Pinkham L, Apter SH, Mohs RC, Davis KL (1993). Schizophrenia-related and affective personality disorder traits in relatives of probands with schizophrenia and personality disorders. Am J Psychiatry. 150:435-442.

Vollema MG, Van den Bosch RJ (1995) The multidimensionality of schizotypy. Schizophr Bull. 21:19-32.

Young HF, Bentall RP, Slade PD, Dewey ME (1986) Disposition towards hallucinations, gender and EPQ scores: A brief report. Pers Indiv Dif. 7:247-249. 


\begin{tabular}{|c|c|}
\hline Age, years (range: 18-26) & $20.1 \pm 1.7$ \\
\hline Gender, male & $188(22.8 \%)$ \\
\hline \multicolumn{2}{|l|}{ Race/ethnicity } \\
\hline White/Caucasian & $371(45.3 \%)$ \\
\hline Black/African American & $251(30.6 \%)$ \\
\hline Asian American & $84(10.3 \%)$ \\
\hline Biracial/Multiracial & $46(5.6 \%)$ \\
\hline Latino/Hispanic & $37(4.5 \%)$ \\
\hline Other & $30(3.7 \%)$ \\
\hline \multicolumn{2}{|l|}{ Relationship Status } \\
\hline Single and not dating anyone regularly & $376(45.6 \%)$ \\
\hline Dating a steady girlfriend or boyfriend & $402(48.7 \%)$ \\
\hline Engaged & $35(4.2 \%)$ \\
\hline Married & $12(1.5 \%)$ \\
\hline History of Mental Health Treatment & $234(28.4 \%)$ \\
\hline \multicolumn{2}{|l|}{ Schizotypy Scales } \\
\hline SPQ Paranoid Subscale (range: 0-25) & $9.8 \pm 5.6$ \\
\hline SPQ Cognitive-Perceptual Subscale (range: $0-16$ ) & $3.9 \pm 3.4$ \\
\hline SPQ Interpersonal Subscale (range: 0-33) & $9.9 \pm 6.8$ \\
\hline SPQ Disorganized Subscale (range: 0-16) & $5.3 \pm 4.1$ \\
\hline Total SPQ Scale (range: 0-74) & $23.0 \pm 13.6$ \\
\hline Perceptual Aberration Scale (range: 0-33) & $4.5 \pm 4.7$ \\
\hline Social Anhedonia Scale (range: 0-31) & $8.7 \pm 6.0$ \\
\hline
\end{tabular}




\begin{tabular}{|c|c|c|c|c|}
\hline Independent Predictors & B & $S E$ & $t$ & $p$ \\
\hline \multicolumn{5}{|c|}{ SPQ Paranoid Domain } \\
\hline History of Treatment & 1.530 & .465 & 3.287 & .001 \\
\hline \multicolumn{5}{|c|}{ SPQ Cognitive-Perceptual Domain } \\
\hline History of Treatment & .941 & .280 & 3.357 & .001 \\
\hline \multicolumn{5}{|c|}{ SPQ Interpersonal Domain } \\
\hline History of Treatment & 1.900 & .564 & 3.370 & .001 \\
\hline \multicolumn{5}{|c|}{ SPQ Disorganized Domain } \\
\hline Race: Black/African American & -1.498 & .460 & -3.254 & .001 \\
\hline Relationship Status & -.939 & .294 & -3.190 & .001 \\
\hline History of Treatment & 1.319 & .326 & 4.050 & $<.001$ \\
\hline \multicolumn{5}{|c|}{ Perceptual Aberration Scale } \\
\hline Race: Black/African American & -1.355 & .576 & -2.354 & .019 \\
\hline \multicolumn{5}{|c|}{ Revised Social Anhedonia Scale } \\
\hline Race: White/Caucasian & -1.599 & .664 & -2.407 & .016 \\
\hline Gender & -2.740 & .527 & -5.197 & $<.001$ \\
\hline
\end{tabular}

* The stepwise entry method was used. Only significant predictors are shown. Unstandardized coefficients and standard errors are given in the columns marked B and SE, respectively. 